\title{
Intragenic duplication of EHMT1 gene results in Kleefstra syndrome
}

\author{
Eva Maria Christina Schwaibold ${ }^{1 *}$, Mateja Smogavec ${ }^{1}$, Elke Hobbiebrunken² ${ }^{2}$ Lorenz Winter ${ }^{1}$, Barbara Zoll', \\ Peter Burfeind ${ }^{1}$, Knut Brockmann² and Silke Pauli ${ }^{1}$
}

\begin{abstract}
Background: Kleefstra syndrome is characterized by intellectual disability, muscular hypotonia in childhood and typical facial features. It results from either a microdeletion of or a deleterious sequence variant in the gene euchromatic histone-lysine N-methyltransferase 1 (EHMT1) on chromosome 9q34.

Results: We report on a 3-year-old girl with characteristic symptoms of Kleefstra syndrome. Array comparative genomic hybridization analysis revealed a 145 kilobases duplication spanning exons 2 to 10 of EHMT1. Sequence analysis characterized it as an intragenic tandem duplication leading to a frame shift with a premature stop codon in EHMT1.
\end{abstract}

Conclusions: This is the first description of an intragenic duplication of EHMT1 resulting in Kleefstra syndrome.

Keywords: Array CGH, EHMT1, Haploinsufficiency, Intragenic duplication, Kleefstra syndrome, KS

\section{Background}

Kleefstra syndrome (KS; OMIM \#610253) is a clinically well described genetic disorder characterized by the phenotypical core features of psychomotoric retardation/ intellectual disability (ID), muscular hypotonia and characteristic facial dysmorphisms. The underlying cause of KS is - in approximately $75 \%$ - a microdeletion in the chromosomal region 9q34 leading to either a partial or an entire EHMT1 loss [1-4]. The other causes of KS are heterozygous intragenic loss-of-function mutations in the EHMT1 gene ( 25\%; OMIM *607001) [1-4]. There seems to be no clear genotype-phenotype correlation regarding patients with microdeletions in 9q34 and intragenic mutations in EHMT1 [3,4]. Duplications of the entire or partial EHMT1 gene have been reported [5,6] but none of these duplications was strictly intragenic and none of them led to a KS phenotype.

EHMT1 encodes for a methyltransferase specific for lysine- 9 of histone $\mathrm{H} 3$ and is a component of the transcription factor E2F6, which can repress gene transcription [7]. E2F6-methylation by EHMT1 is probably

\footnotetext{
* Correspondence: eva.schwaibold@med.uni-goettingen.de ${ }^{1}$ Institute of Human Genetics, Georg August University, Heinrich-Düker-Weg 12, 37073 Göttingen, Germany

Full list of author information is available at the end of the article
}

important for transcriptional inactivation via chromatin remodeling [7].

Here, we describe for the first time a patient with the typical symptoms of KS carrying a 145 kilobases $(\mathrm{kb})$ intragenic duplication in the EHMT1 gene. The submicroscopic duplication in EHMT1 was detected by array comparative genomic hybridization (aCGH). Transcript analysis revealed a tandem duplication leading to a frame shift and a premature stop codon, suggesting haploinsufficiency as the underlying cause of KS $[1,3,8]$.

\section{Case presentation \\ Case report}

The patient is the third child of healthy non-consanguinous parents. She has two healthy older brothers. Her mother had an intellectually disabled half-brother. Her father's paternal uncle died directly after birth for unknown reasons. Prenatal ultrasound demonstrated a fetal constitutional growth delay, a polyhydramnion and a single umbilical artery. The girl was born spontaneously at 39 weeks gestation. Her birth length, her birth weight and her head circumference were between the $3^{\text {rd }}$ and the $10^{\text {th }}$ centile. Apgar scores were 9/9/9.

Developmental delay was first noted at 3 months of age. The girl showed marked muscular hypotonia. At 2 years 
of age she could sit without support but was still not able to crawl or walk at the age of 3 years.

She tended to be very quiet and did not react to sounds. A hearing test was anamnestically normal. The girl began to vocalize and starts teeth grinding when she was one year old but she could not speak at the age of 3 years.

She displayed autistic features with stereotypic movements and the vocalization of clicking voices with her tongue. At 3 years of age she attended a special nursery.

Cranial MRIs at the age of 2 and 3 years, respectively, revealed unspecific bilateral T2-hyperintense white matter changes in the occipital region. An electroencephalogram at the age of 3 years was normal.

Echocardiography demonstrated a haemodynamically irrelevant patent foramen ovale and a mild peripheral pulmonary stenosis. Myocardial function was normal.

At 2 11/12 years of age the patient displayed the following facial features (Figure 1a-b): square, brachycephalic face with a prominent forehead and frontal bossing, slight midface hypoplasia, hypertelorism with mildly downslanting palpebral fissures, synophris, small nose with anteverted nostrils and deep-set nasal root, mild prognathism, deep-set posterior rotated ears, full cheeks and prominent philtrum. The girl held her mouth mostly opened with a cupid bowed upper lip, full lower lip and a slightly protruding tongue. An ophthalmologic examination confirmed an intermittent exotrophy. The patient's soles of the feet were deeply creased in their frontal part (Figure 1c). Her back was hairy (Figure 1d).

\section{Results}

Array CGH analysis in our patient revealed a subterminal duplication on chromosome 9q34.4. The size was approximately $145 \mathrm{~kb}$, spanning positions 140.535 .164 to 140.657 .526 (arr 9q34.3(140,527,261x2,140,535,164140,657,526x3,140,672,499x2); GRCh37/hg19; ISCN 2013; Figure 2a). The duplication was verified by qPCR (data not shown). The parents' array CGH analyses as well as standard karyotyping were normal (data not shown) confirming the de novo origin of the duplication.

The only gene in the duplicated region was EHMT1 (Figure 2a). According to the array CGH results the centromerically located breakpoint of the duplication was within intron 1 of EHMT1, the terminally located breakpoint was between intron 10 and exon 13 of EHMT1. As microdeletions as well as sequence variants but not microduplications of or within EHMT1 are known to cause KS and our patient's symptoms were typical for KS the possible pathogenic background was examined.

First, the terminal breakpoint of the duplication was narrowed down to intron 10 of EHMT1 by qPCR using exon-specific primers for the chromosomal region between positions 140.535 .164 to 140.657 .526 . It was demonstrated that the duplication spanned exon 2 to exon 10 of EHTM1 (data not shown). There were several possibilities regarding the localization and the orientation of the duplication but one of the two RNA transcripts shown in Figure 2b seemed most likely. Therefore, PCRs with the patient's cDNA and primer sequences specific for the possible PCR products A (exon 10 adjacent to exon 2 of the coding EHTM1 gene) and B (exon 2 adjacent to exon 11 of the coding EHTM1 gene), respectively, were performed. Primers for the PCR product of exon 10 adjacent to exon 11 and the PCR product spanning exons 2 to 10, respectively, were used as positive controls for the primer function (data not shown). A PCR product was only obtained for A (Figure 2c, first lane) and for the positive controls (data not shown), not for $\mathrm{B}$ (Figure 2c, second lane) and not with the DNA sample of a control person (Figure 2c, third and fourth lane). By obtaining this PCR product transcript degradation that would be suggestive for nonsense mediated mRNA decay seemed to be rather unlikely. PCR product A was directly sequenced and compared with the sequences of both, exon 2 and exon 10, in wildtype EHMT1 (ENST00000460843). The duplication within EHMT1 resulted in a frameshift and a premature stop codon in the
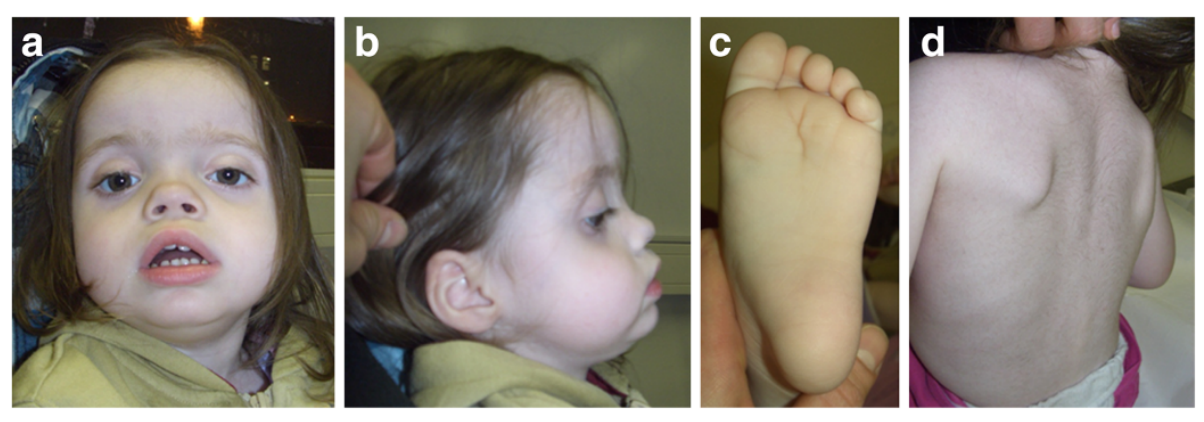

Figure 1 Representative photographs of the patient at 2 11/12 years of age. (a-b) The main facial features of the girl were: brachycephaly, prominent forehead, hypertelorism with mildly downslanting palpebral fissures, intermittent exotrophy, synophris, small nose with anteverted nostrils and deep-set nasal root, mild prognathism, deep-set posterior rotated ears, full cheeks and prominent philtrum. Note the mostly opened mouth with cupid bowed upper lip and full lower lip. (c) The frontal part of her plantar feet was deeply creased. (d) Her back was hairy. 

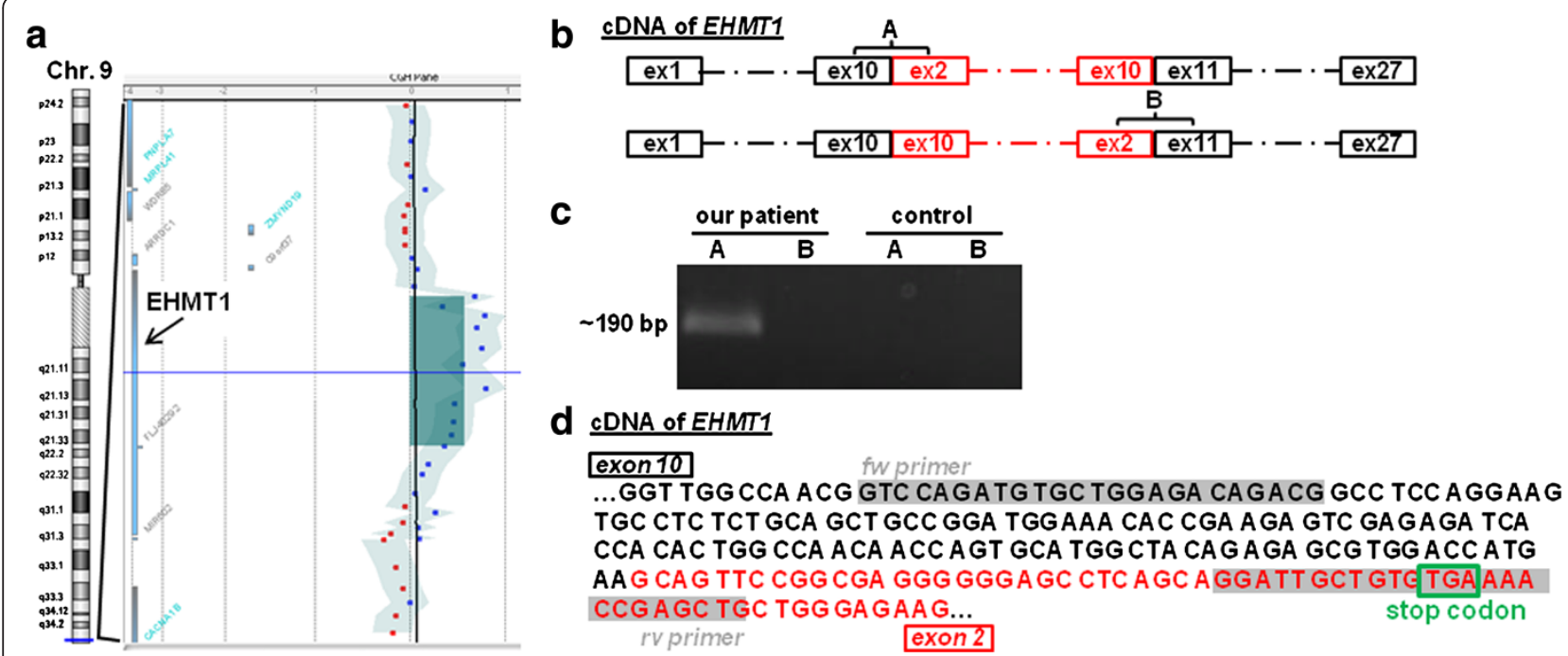

Figure 2 Microduplication within EHMT1 gene results in KS. (a) aCGH identified a $145 \mathrm{~kb}$ duplication (greenish shaded; enlarged on the right side of Figure 2a) within the EHMT1 gene (arrow) on chromosome 9q34.4. Log 2 ratio data for two dye-swap plots (patient/control) are presented according to their positions in the human genome. The light blue shaded region with blue and red dots indicates the moving average. Chr.9: chromosome 9. (b) Schematic overview of the two possible cDNA transcripts of EHMT1 gene in our patient that seemed most likely. Black: normal EHMT1 gene transcript. Red: duplicated region of EHMT1 in our patient. ex: exon. A: indicates a possible PCR product (exon 10 of the duplicated region adjacent to exon 2 of the normal EHMT1 transcript). B: indicates a possible PCR product (exon 2 of the duplicated region adjacent to exon 11 of normal coding EHTM1 transcript). (c) Agarose gel electrophoresis of possible PCR products A and B (see Figure 2b) in our patient (first and second lane) and a control person (third and forth lane). A PCR product was only seen for A in our patient. It showed the expected size of $\sim 190$ bp of PCR product A according to the 1 kb Plus DNA Ladder (Invitrogen, Carlsbad, CA). (d) Sequence analysis of PCR product A (Figure 2c) and comparison with the normal coding transcript of EHTM1 gene revealed a frameshift in the coding sequence leading to a premature stop codon (green box) in EHMT1 in our patient. Exon 10 adjacent to exon 2 of the forward strand of EHMT1 coding sequence in our patient is shown. Grey shaded boxes: localization of the constructed forward (fw) and reverse (rv) primers, respectively. Black: coding sequence of exon 10 of EHMT1. Red: coding sequence of exon 2 of EHMT1.

additionally inserted exon 2 of the EHMT1 transcript in our patient (Figure 2d).

\section{Discussion}

Array CGH revealed a $145 \mathrm{~kb}$ duplication within the EHMT1 gene in our patient (Figure 2a). A detailed analysis of the duplicated region within EHMT1 in our patient by $\mathrm{qPCR}$ and cDNA analysis revealed a direct tandem duplication of exons 2 to 10 of the EHMT1 gene (Figure 2c).

Patients with duplications in the region of EHMT1 have been reported $[5,6]$ but the duplications included either the whole EHMT1 gene, additionally the adjacent chromosomal region or one or multiple adjacent genes. Only one patient with a EHMT1 duplication spanning exons 1 to 16 is described in the literature [5]. This patient does not display a KS phenotype but autistic features and behavioral problems [5]. The patient had a tandem duplication with both copies of EHMT1 being probably functional. Due to the duplication in our patient a premature stop codon in the additionally inserted exon 2 is generated (Figure 2d). It is very likely that the premature termination of the protein EHMT1 will impair or reduce its function although we could not directly prove haploinsufficiency of EHMT1. In contrast, increased dosage of EHMT1 - as in the other patient - might lead to neurodevelopmental impairment [5].

A possible explanation for the location of the duplication in our patient could be the existence of repetitive DNA elements in EHMT1 in the breakpoint region of the duplication. Repetitive DNA elements in general and Alu elements in particular - are prone for non-allelic homologues recombinations that can lead to disease causing chromosomal aberrations [9]. According to the RepeatMasker Web Server [10] both, intron 1 and intron 10 of EHMT1 gene, contain high amounts of repetitive DNA elements (intron 1: 58,13\% total interspersed repeats (TIRs); intron 10: 49,07\% TIRs). The adjacent introns 2, 9 and 11, respectively, have lower amounts of repetitive elements. In intron 1 especially the amount of Alu elements that belong to the short interspersed elements was higher than in intron 2 (31,53\% vs. $19.30 \%)$. The high rate of repetitive elements - especially Alu elements - in the breakpoint regions of the duplication in our patient provides a plausible explanation for the localization of the duplication. Likely, there will be further KS patients with deletions or duplications leading to haploinsufficiency of 
EHMT1 with chromosomal breakpoints in one or both of the affected introns reported here.

Our patient displayed the typical phenotype of KS [1-4,11]; (Table 1). Only minor phenotypical differences were observed, e.g. our patient had a very hairy back and was almost underweight, both features not typically seen in KS.

\section{Conclusions}

For the first time we could show that a duplication within the EHMT1 gene leads to KS in a patient due to

Table 1 Clinical findings of our patient compared with previously reported KS patients and defects in EHMT1

\begin{tabular}{|c|c|c|}
\hline Overlapping features & $\begin{array}{l}\text { Our } \\
\text { patient }\end{array}$ & $\begin{array}{l}\text { Previously reported } \\
\text { patients with KS and } \\
\text { EHMT1 defect (\%) }\end{array}$ \\
\hline Psychomotoric retardation/ ID & + & $100 \%$ \\
\hline Childhood hypotonia & + & $100 \%$ \\
\hline Behavioural problems & $\begin{array}{c}+ \\
\text { (autistic features) }\end{array}$ & $75 \%$ \\
\hline \multicolumn{3}{|l|}{ Facial dysmorphisms: } \\
\hline Midface hypoplasia & + & $80 \%$ \\
\hline Synophris & + & $60 \%$ \\
\hline $\begin{array}{l}\text { Dysplastic/posterior } \\
\text { rotated ears }\end{array}$ & + & $50 \%$ \\
\hline Short/small nose & + & $45 \%$ \\
\hline Brachycephaly & + & $40 \%$ \\
\hline $\begin{array}{l}\text { Protruding tongue/ } \\
\text { macroglossia }\end{array}$ & + & $40 \%$ \\
\hline Hypertelorism & + & $30 \%$ \\
\hline Anteverted nostrils & + & $25 \%$ \\
\hline $\begin{array}{l}\text { Tented/cupid-bowed } \\
\text { upper lip }\end{array}$ & + & $25 \%$ \\
\hline Thick/everted lower lip & + & $25 \%$ \\
\hline Pointed chin & + & $25 \%$ \\
\hline \multicolumn{3}{|l|}{ Different features } \\
\hline Overweight & - & $45 \%$ \\
\hline \multicolumn{3}{|l|}{ Facial dysmorphisms: } \\
\hline Arched eyebrows & - & $30 \%$ \\
\hline Pointed chin & - & $25 \%$ \\
\hline Prominent forehead & + & n. r. \\
\hline \multicolumn{3}{|l|}{ Neurologic defects: } \\
\hline Structural CNS anomalies & - & n. r. \\
\hline Seizures & - & $25 \%$ \\
\hline Renal anomalies & - & $15 \%$ \\
\hline Sensorineural hearing loss & - & $15 \%$ \\
\hline Deeply creased soles of the feet & + & n. r. \\
\hline Hairy back & + & n. r. \\
\hline
\end{tabular}

+ denotes present, - denotes absent; n. r. = not reported; $\mathrm{KS}=$ Kleefstra syndrome; ID = intellectual disability; Table modified from [11]. the creation of a premature stop codon in EHMT1 that will probably impair/reduce the protein function. The gene EHMT1 seems to be dosage sensitive with a decrease of gene expression resulting in $\mathrm{KS}$ and an increase of gene expression leading to a milder phenotype with an impaired neurodevelopment. The phenotype displayed by our patient is very similar compared with the previously reported KS patients and confirms the notion that there is no strong genotype-phenotype correlation in KS.

\section{Methods}

\section{DNA and RNA preparation}

Blood samples were collected from the patient and her parents after obtaining the parents' signed informed consent. Total genomic DNA was prepared using standard techniques. RNA isolation was performed from a blood sample of our patient using the PAXgene ${ }^{\mathrm{mm}}$ Blood RNA kit 50v2 (PreAnalytix, Qiagen, Venlo, The Netherlands) according to the manufacturer's instructions. cDNA was obtained using the Superscript II Kit (Invitrogen, Carlsbad, CA).

aCGH

Genome-wide copy number scans were performed with the patient's and her parents' lymphocyte DNA using an Agilent SurePrint G3 Human CGH Microarray Kit $4 \times$ $180 \mathrm{~K}$ and was read using an Agilent Microarray Scanner G256BA and G5761A, respectively, along with Agilent Feature Extraction Software V9.1 (Agilent Technologies, Inc., Santa Clara, CA) according to the manufacturer's instructions. The results were analyzed using Agilent Cytogenomics 2.0 and 2.5 software, respectively. Array CGH data was confirmed by quantitative real time PCR (qPCR).

\section{EHMT1 gene analysis}

qPCR was used to narrow down the C-terminal breakpoint in the EHMT1 gene by designing specific primers for exon 6 to 17 of the EHMT1 gene (ENST00000460843). PCRs were performed to amplify the possible transcripts of the EHMT1 gene in our patient. The obtained PCR products were directly sequenced on the $\mathrm{ABI} 3500 \mathrm{xL}$ Genetic Analyzer (Applied Biosystems, Foster City, CA). Their sequence was compared with the sequence of normal EHMT1 coding transcript (ENST00000460843). All primer sequences and PCR conditions are available on request.

\section{Cytogenetic analysis}

Metaphase chromosome spreads of blood samples of the patient's parents were prepared from phytohemagglutinin (PHA)-stimulated peripheral blood cultures using standard protocols. 10 and 11, respectively, GTG-banded metaphases were analyzed. 


\section{Consent}

Written informed consent was obtained from the parents of the patient for publication of this Case report and any accompanying images. A copy of the written consent is available for review by the Editor-in-Chief of this journal.

\section{Competing interests}

The authors declare that they have no competing interests.

\section{Authors' contributions}

EMCS was the genetic counselor of the patient's parents, co-evaluated the patient's aCGH analysis, designed the study (especially the cDNA analysis) and drafted the manuscript. MS analyzed most of the aCGH data. EH and KB were responsible for the medical treatment of the patient. KB helped with the final version of the manuscript. LW carried out most of the molecular genetic studies (aCGH, qPCR, sequence analysis). PB was responsible for the $\mathrm{aCGH}$ analysis and helped with the final version of the manuscript. BZ helped with the genetic counseling of the patient's parents. SP helped designing the study and drafting the final version of the manuscript. All authors read and approved the final manuscript.

\section{Acknowledgements}

We would like to thank the parents of the patient for their cooperation and permission to publish photographs of the patient. Additionally, we are grateful to Wolfgang Engel for his support and his critical reading of the manuscript. We thank Sabine Herold for excellent technical assistance.

\section{Author details}

${ }^{1}$ Institute of Human Genetics, Georg August University, Heinrich-Düker-Weg 12, 37073 Göttingen, Germany. ${ }^{2}$ Department of Pediatrics and Pediatric Neurology, Georg August University, Robert-Koch-Str. 40, 37075 Göttingen, Germany.

Received: 27 August 2014 Accepted: 14 October 2014

Published online: 23 October 2014

\section{References}

1. Kleefstra T, Brunner HG, Amiel J, Oudakker AR, Nillesen WM, Magee A, Geneviève D, Cormier-Daire V, van Esch H, Fryns JP, Hamel BC, Sistermans EA, de Vries BB, van Bokhoven $\mathrm{H}$ : Loss-of-function mutations in euchromatin histone methyl transferase 1 (EHMT1) cause the 9q34 subtelomeric deletion syndrome. Am J Hum Genet 2006, 79:370-377.

2. Stewart DR, Kleefstra $\mathrm{T}$ : The chromosome $9 \mathrm{q}$ subtelomere deletion syndrome. Am J Med Genet C: Semin Med Genet 2007, 145C:383-392.

3. Kleefstra T, van Zelst-Stams WA, Nillesen WM, Cormier-Daire V, Houge G, Foulds $\mathrm{N}$, van Dooren M, Willemsen MH, Pfundt R, Turner A, Wilson M, McGaughran J, Rauch A, Zenker M, Adam MP, Innes M, Davies C, López AG, Casalone R, Weber A, Brueton LA, Navarro AD, Bralo MP, Venselaar $H$, Stegmann SP, Yntema HG, van Bokhoven H, Brunner HG: Further clinical and molecular delineation of the $9 \mathrm{q}$ subtelomeric deletion syndrome supports a major contribution of EHMT1 haploinsufficiency to the core phenotype. J Med Genet 2009, 46:598-606.

4. Willemsen MH, Vulto-van Silfhout AT, Nillesen WM, Wissink-Lindhout WM, van Bokhoven $\mathrm{H}$, Philip N, Berry-Kravis EM, Kini U, van Ravenswaaij-Arts CM, Delle Chiaie B, Innes AM, Houge G, Kosonen T, Cremer K, Fannemel M, Stray-Pedersen A, Reardon W, Ignatius J, Lachlan K, Mircher C, van den Enden PT H, Mastebroek M, Cohn-Hokke PE, Yntema HG, Drunat S, Kleefstra T: Update on Kleefstra syndrome. Mol Syndromol 2012, 2:202-212.

5. Yatsenko SA, Hixson P, Roney EK, Scott DA, Schaaf CP, Ng YT, Palmer R, Fisher RB, Patel A, Cheung SW, Lupski JR: Human subtelomeric copy number gains suggest a DNA replication mechanism for formation: beyond breakage-fusion-bridge for telomere stabilization. Hum Genet 2012, 131:1895-1910.

6. Tomita-Mitchell A, Mahnke DK, Struble CA, Tuffnell ME, Stamm KD, Hidestrand M, Harris SE, Goetsch MA, Simpson PM, Bick DP, Broeckel U, Pelech AN, Tweddell JS, Mitchell ME: Human gene copy number spectra analysis in congenital heart malformations. Physiol Genomics 2012, 44:518-541.
7. Ogawa H, Ishiguro K, Gaubatz S, Livingston DM, Nakatani Y: A complex with chromatin modifiers that occupies E2F- and Myc-responsive genes in G0 cells. Science 2002, 296:1132-1136.

8. Kleefstra T, Smidt M, Banning MJG, Oudakker AR, Van Esch $H$, de Brouwe AP, Nillesen W, Sistermans EA, Hamel BC, de Bruijn D, Fryns JP, Yntema HG, Brunner $\mathrm{HG}$, de Vries BB, van Bokhoven $\mathrm{H}$ : Disruption of the gene euchromatin histone methyl transferase1 (Eu-HMTase1) is associated with the 9q34 subtelomeric deletion syndrome. J Med Genet 2005, 42:299-306.

9. Deininger PL, Batzer MA: Alu repeats and human disease. Mol Genet Metab 1999, 67:183-193.

10. RepeatMasker Web Server [http://www.repeatmasker.org]

11. Kleefstra T, Kramer JM, Neveling K, Willemsen MH, Koemans TS, Vissers LE, Wissink-Lindhout W, Fenckova M, van den Akker WM, Kasri NN, Nillesen WM, Prescott T, Clark RD, Devriendt K, van Reeuwijk J, de Brouwer AP, Gilissen C, Zhou H, Brunner HG, Veltman JA, Schenck A, van Bokhoven H: Disruption of an EHMT1-associated chromatin-modification module causes intellectual disability. Am J Hum Genet 2012, 91:73-82.

doi:10.1186/s13039-014-0074-7

Cite this article as: Schwaibold et al:: Intragenic duplication of EHMT1 gene results in Kleefstra syndrome. Molecular Cytogenetics 2014 7:74.

\section{Submit your next manuscript to BioMed Central and take full advantage of:}

- Convenient online submission

- Thorough peer review

- No space constraints or color figure charges

- Immediate publication on acceptance

- Inclusion in PubMed, CAS, Scopus and Google Scholar

- Research which is freely available for redistribution 